\title{
ADJUSTED ENERGY BENCHMARKING SYSTEM UNDER COVID CONDITIONS: DUBAI AS CASE STUDY
}

\author{
JUAN DAVID BARBOSA, MIN LIN \& EDWIN RODRIGUEZ-UBINAS \\ DEWA R\&D Center, Dubai Electricity and Water Authority, United Arab Emirates
}

\begin{abstract}
Since COVID-19 emerged in late 2019, governments and local authorities have drawn up policies to mitigate the impact of the virus and protect their population. They implement preventive measures that include sanitary guidelines and rules related to people's mobility and social interactions. Such efforts have disrupted business, educational, and social activities, requiring the adaptation of the people to a new reality that, consequently, has shifted their energy demand patterns. These changes in the energy demand bring challenges to the energy benchmarking efforts, which has been an effective steppingstone for improving the energy performance, allowing users to compare their consumption relative to others and detect the opportunities for improvement from the current state. Also, the changes in the consumption patterns also make it challenging to identify and target underperforming users. Consequently, in this study, we propose an adjusted benchmarking system that accounts for the impact of COVID-19 on the energy consumption patterns of Dubai using available public data. We utilized monthly electrical consumption and dwelling profile data from 1,841 residential buildings between January 2020 and June 2021. We built two different statistical models, a pre-covid and post-covid model, according to different characteristics of the dwellings such as gross floor area, number of users, a cooling source, and time-dependent weather variables such as outdoor temperature. Finally, we compare both models to underline the significance of COVID-19 in the adjusted energy benchmarks. The resulting adjusted model serves to estimate the average consumption of residents in Dubai throughout the year. Furthermore, both models' difference helps define the adjusted range of the users over/underperforming. The findings and conclusions of this study demonstrate the need for built adjusted benchmarking systems to continue effectively categorizing users' energy consumption under unusual conditions such as COVID-19.
\end{abstract}

Keywords: energy consumption, Dubai, COVID-19, energy benchmarks.

\section{INTRODUCTION}

COVID-19 has challenged the traditional ways of living and interacting around the world. Since the virus appeared in late 2019, it has resulted in more than 200 million recorded cases and over 4.3 million deaths as of August 2021 [1]. As a response to the health crisis, governments and local authorities restricted mobility and social interactions by implementing curfews, full lockdowns, and border closing [2]. Social interactions have been reduced by either closing most public events and facilities, or limiting their capacities [3]. Such measures have disrupted everyday activities both for businesses and people, requiring them to adapt to new social dynamics, and consequently, shifting their energy demand patterns. With reduced mobility, there is a wide acceptance of work from home, distance learning, and online shopping that transferred many daily urban activities to households.

Understanding the impact of the pandemic on energy demand trends in cities is important for government and policy developers as it can help to quantify and forecast the effect of the implemented policies but also provide insight for future adaptations and energy efficiency policies. Dubai took a proactive and dynamic response to mitigate the effects of COVID-19, implementing multiple measures that reshaped its population's activities. Protocols were introduced timely and updated through the development of the pandemic. As an example, in 
the National Disinfection Program and social distancing program targeted at the pandemic, Dubai closed all international borders on March 23, 2020 [4], had a curfew period between March 30, 2020 and June 24, 2020, and a full lockdown between April 4, 2020 and April 26, 2020 [4]. Additionally, on March 25, 2020 [5] most non-essential businesses were asked to close and only until April 26, 2020, businesses such as cafes and dine-ins were allowed to resume activities limited to $30 \%$ of their capacity [4]. A comprehensive and fast vaccination program was introduced since December 2020 to ensure the safety of the public and accelerate the back-to-normal path.

In the same way, as part of the Exceptional Rules and Regulations, the authorities defined a series of guidelines to promote remote work and digital transformation of businesses through virtual environments [6]. Consequently, changes in the habits of the population of Dubai were reflected in other reports such as Google's COVID-19 Community Mobility Reports, where they estimated that for the month of April 2020 there was a $-65 \%$ average reduction of activity in retail and recreation, grocery and pharmacy, parks, transit stations and workplace areas, while the overall time people spent in their residence had an average increase of 30\% [7]. The main actions taken by the local government are presented below which result in the timeline shown in Fig. 1.

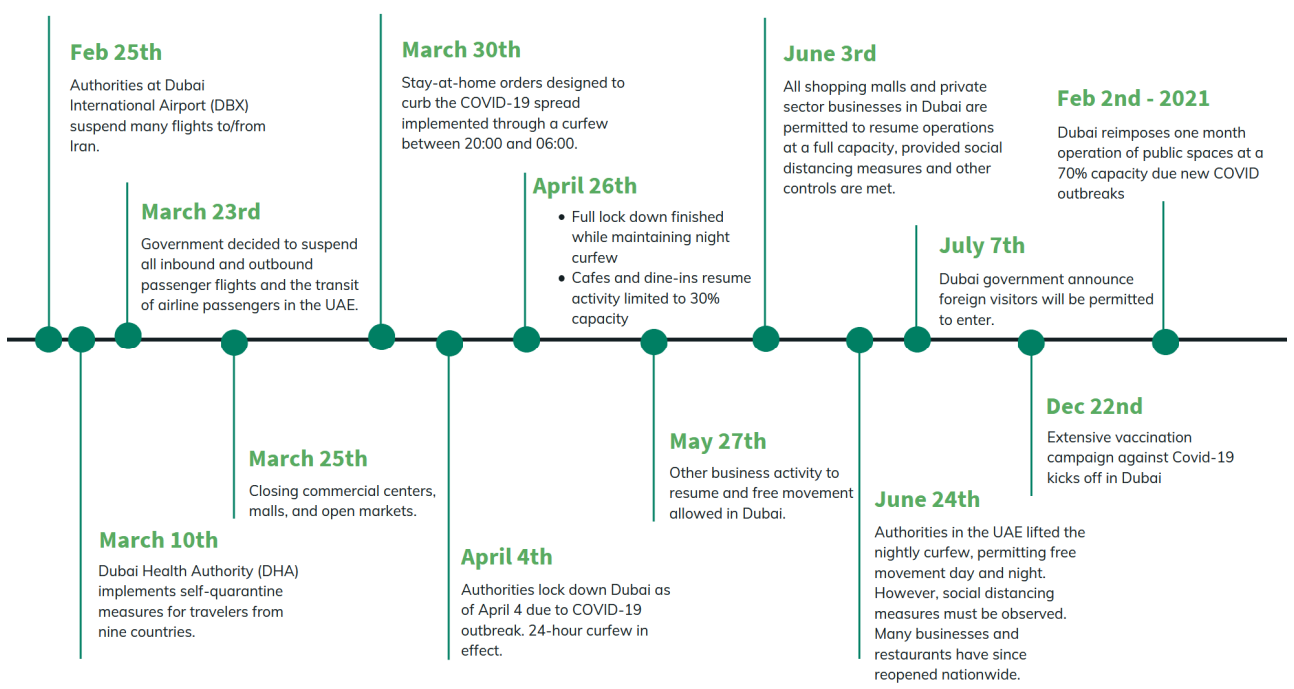

Figure 1: Timeline for COVID-19 containment actions in Dubai.

With the dynamic response towards COVID, people adapt to a new lifestyle and therefore potentially shift their consumption patterns [8]. This poses a challenge to existing benchmarking systems, which are commonly used as an indicator to identify low performers and guide retrofitting efforts. The variation of energy consumption caused by unique events such as pandemics undermine the accuracy of the benchmarking system. It needs to be addressed and included in the energy benchmarking system to ensure the accuracy and set the correct path for efficient retrofits. This study aims to study the variation of consumption records during COVID period and establish an adjusted benchmarking system to account for the unique incident. 


\section{LITERATURE REVIEW}

Some countries like Poland and Australia experienced an increase of $16 \%$ and $15 \%$ respectively of the household energy demand due to the COVID-19 pandemic [8], [9]. On the other hand, sectors such as the information and technology sectors have benefited due to increase in the usage of technology for remote work and business transactions [10]. Overall, the information technology sector has grown during the pandemic. The share of the IT sector went up by nearly $24 \%$ for the first two-quarters of 2020 [11]. Such changes in the location and nature of business activity inevitably alters the energy demand patterns [12].

With the variation in energy consumption caused by the pandemic, it raises a question of whether existing benchmarking system needs to be adjusted to ensure accurate comparison. Energy benchmarking has been widely used to evaluate the energy performance of buildings around the world. Two approaches are commonly taken to establish the benchmarking system, a data-supported top-down approach and a simulation-based bottom-up approach [13]. For instance, Tereci et al. [14] benchmarked German residential buildings with different configuration through EnergyPlus. Same simulation tool is used in Shabunko et al. [15] to benchmark residential buildings in Brunei. Results are compared with actual consumption to identify retrofit opportunities. On the other hand, Ding and Liu [16] reviews existing datadriven methods for benchmarking. Arjunan et al. [17] use public data to suggest potential improvement for the Energy star portfolio manager program.

Existing literature has shown the importance of an accurate benchmarking system and the approaches to establish them. Under the influence of the global pandemic, we aim to investigate the need for an adjusted benchmarking system using user information and consumption data in Dubai. Results will serve to guide future benchmarking efforts and retrofitting opportunities.

\section{METHOD}

This study used anonymized data generated from a survey conducted by the Dubai Electricity and Water Authority (DEWA) as part of its "My Sustainable Living" program [18] which targets only residential users. This initiative aims to enhance the efficiency of electricity and water consumption of residential customers and support them to adopt a sustainable lifestyle. We listed the questions and answers options in Table 1.

The results are combined with the anonymized monthly electrical consumption, published by DEWA on the public data sharing portal of Dubai [19] by matching the account number of registered users. Ideally, higher frequency data such as hourly or by minute would reveal changes in daily patterns. However, publicly available data for Dubai is only shared on a monthly scale. Since we aim to investigate the need for an adjusted benchmarking system, only users with continuous records from 2019 onwards are selected in this study. August 2020 shows missing consumption records for most users. Therefore, this month is excluded from the analysis. 1,841 residential accounts result after matching users that have had continuous records in both years, and that are also registered in the "My sustainable living" survey.

Typical benchmarking structures use energy utilization index (EUI) which expresses the buildings' energy use as a function of their gross floor area in $\mathrm{kWh} / \mathrm{m}^{2}$ per year. However, given the structure of the survey collects gross floor area as a categorical variable, this study decided to define the variable of interest as the absolute consumption of the household in $\mathrm{kWh}$ instead of the EUI [20]-[23].

The methodology followed initially plots consumption values to find its general distribution. Additional consumption plots are made against the survey results to identify 
Table 1: Survey questions.

\begin{tabular}{|l|l|}
\hline Questions & Answer options \\
\hline & I don't know \\
& Less than 50 \\
$50-100$ \\
$\begin{array}{l}\text { Can you estimate the surface area of your } \\
\text { home (in } m^{2} \text { )? }\end{array}$ & $100-150$ \\
& $150-200$ \\
& $200-300$ \\
& More than 300 \\
\hline $\begin{array}{l}\text { If you live in a villa, do you have your own } \\
\text { swimming pool? }\end{array}$ & Y/N \\
\hline $\begin{array}{l}\text { If you live in a villa, do you have your own } \\
\text { garden? }\end{array}$ & Y/N \\
\hline How many people live in your home? & Incremental increase from 0 to 8 with 9 \\
and above
\end{tabular}

relevant groupings and patterns that explain the observed distribution and unveils energy drivers. Secondly, effects of covid on the monthly consumption distribution are studied with statistical tests in between the two years. Thirdly, a regression model is generated using energy driver variables and a dummy variable that identifies months when the Emirate declared reduced mobility policies. Finally, the generated model and the characterized distributions will serve to benchmark energy consumption for residential users in Dubai.

\section{RESULTS AND DISCUSSION}

When observing the distribution of the consumption in kWh in Fig. 2, the double hump pattern shows there are at least 2 variations of user accounts. In Dubai, there are several ways to bill users' electricity and cooling consumption as shown in Table 1. People who use district cooling as their main cooling sources have separate bills for cooling, leaving it excluded from their electricity bills. It therefore reveals the baseload of users in the electricity bills. The rest either has the cooling consumption included in their monthly electricity bills or being a part of their rent. When generating a distribution plot for all the variables, it is noticed that separating users whose cooling is included as part of their bill, and users that separate their 
cooling needs from their electricity bills, either by having a separated district cooling service or including cooling costs in their rent (Fig. 3), the double hump distribution of consumption is decomposed to two distributions.

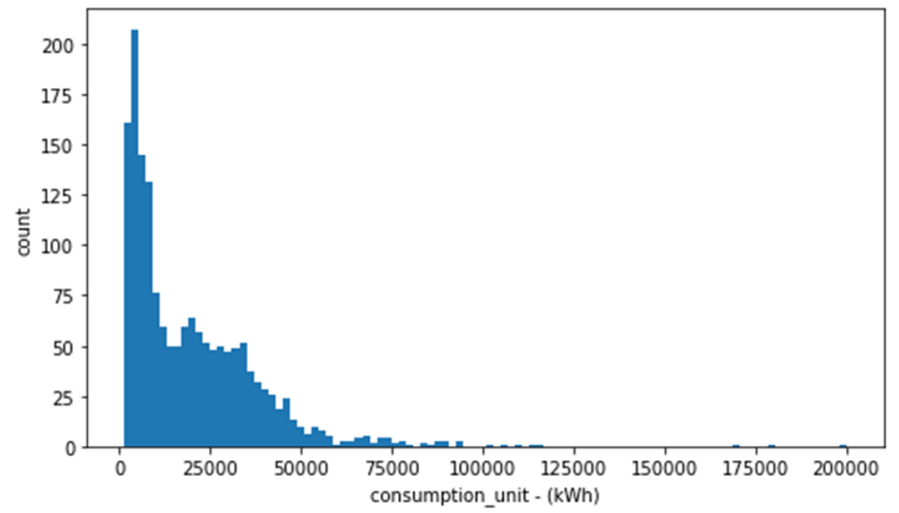

Figure 2: Annualized consumption distribution (kWh).

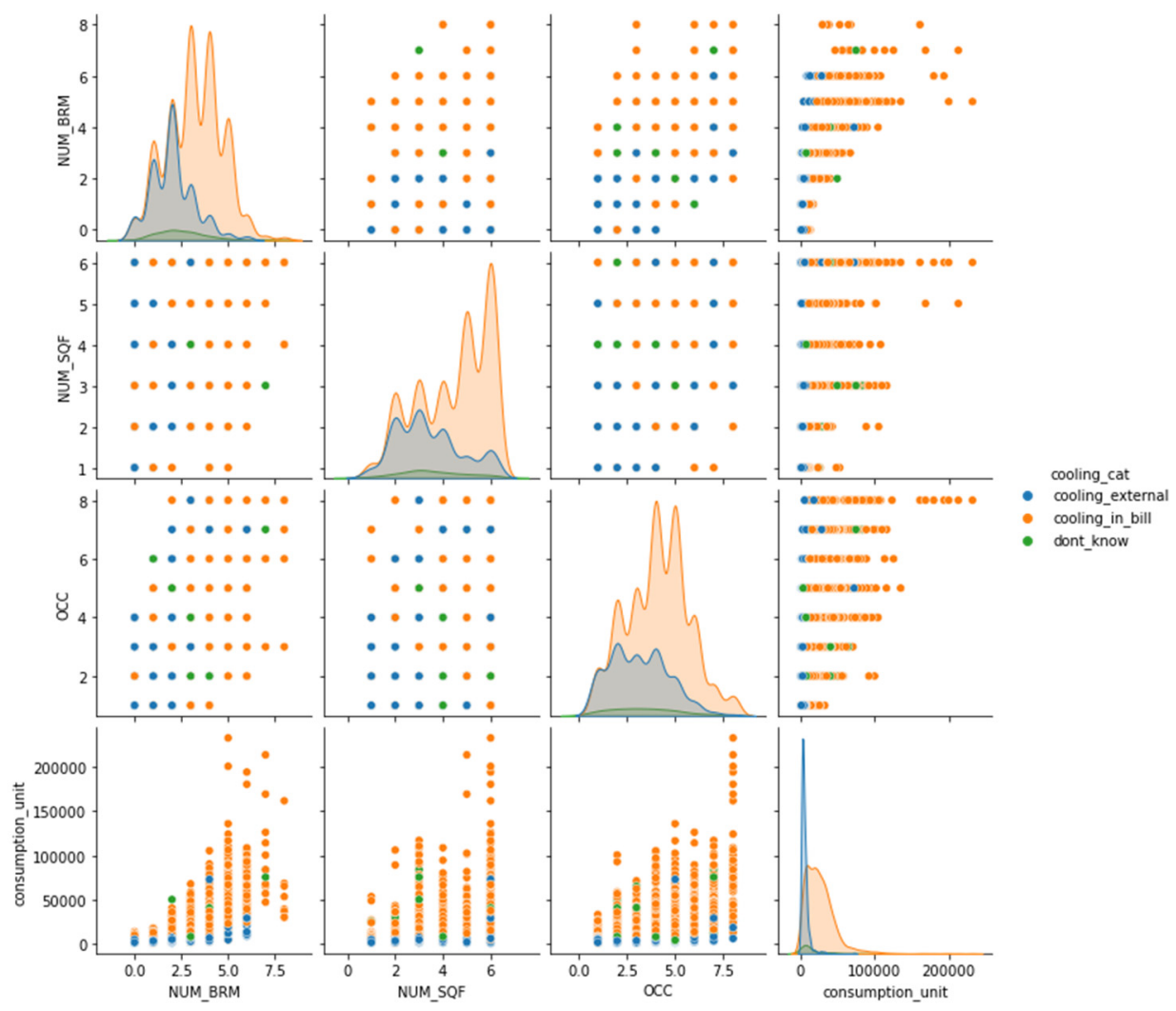

Figure 3: Variable relationships. 

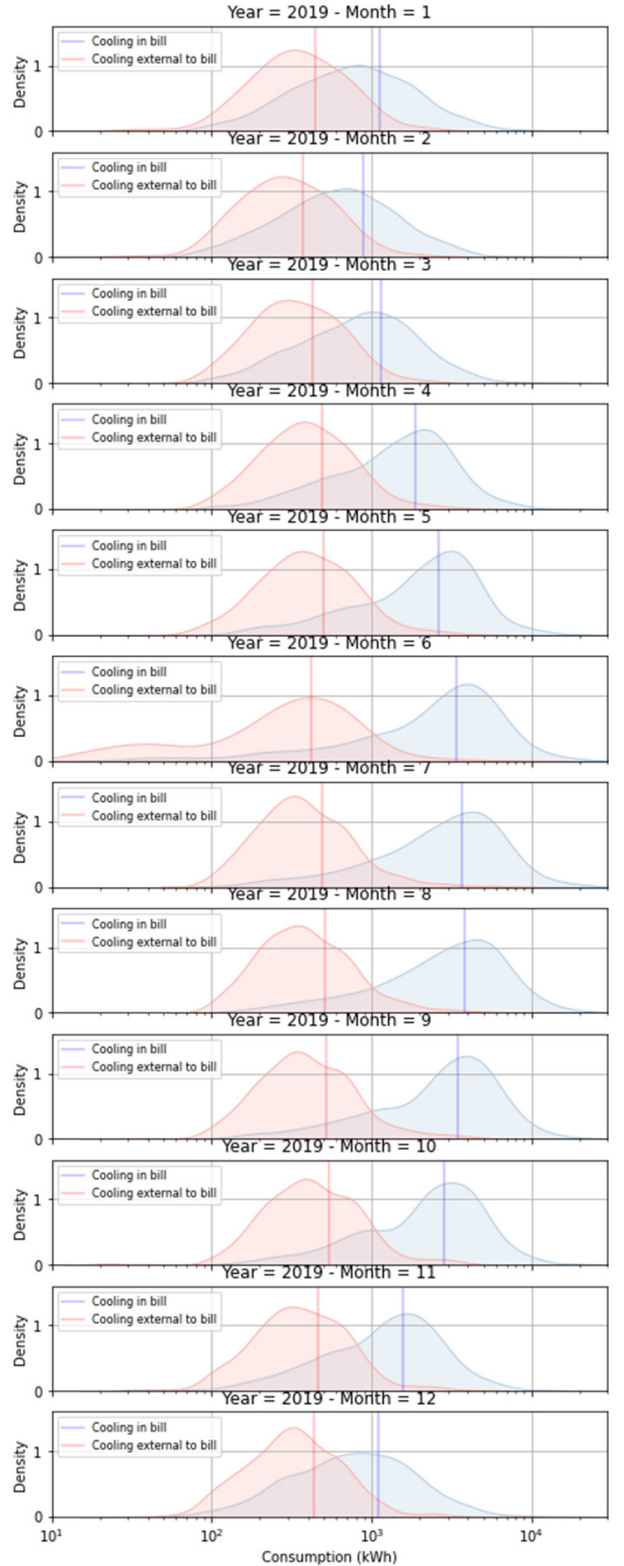
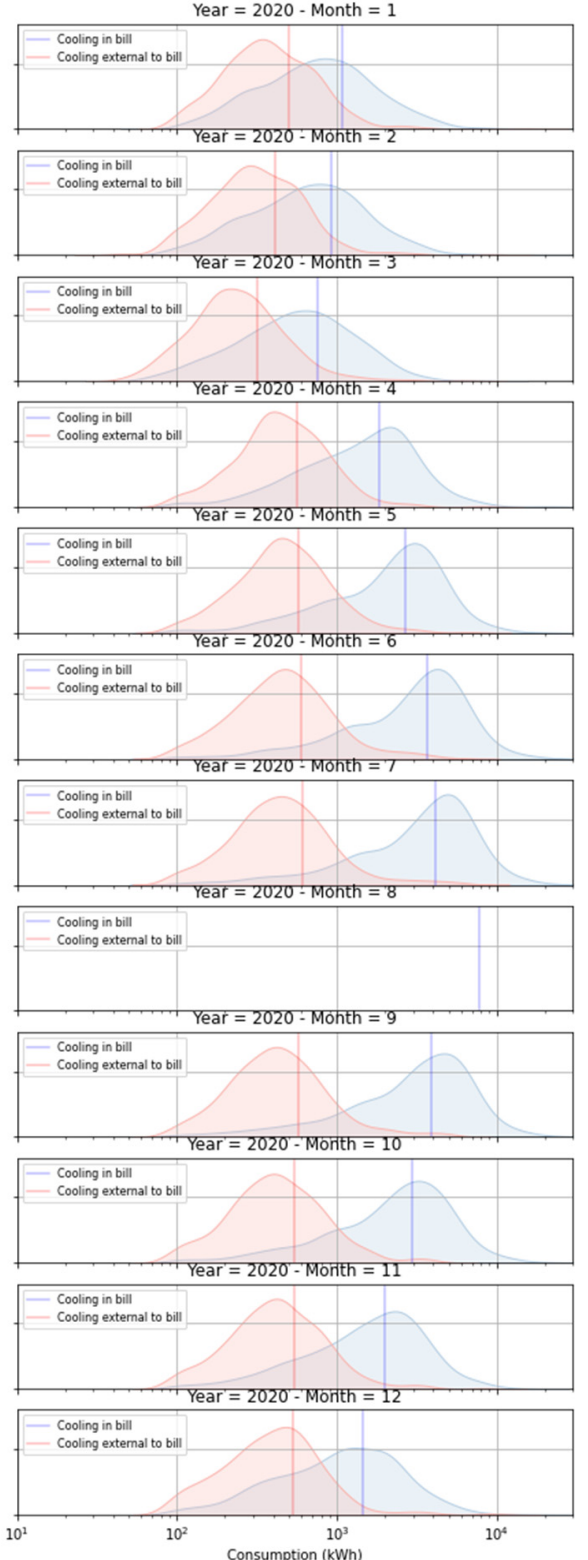

Figure 4: Monthly consumption according to cooling category. Vertical line shows means.

As a result of the close relation between cooling consumption and seasonal weather, monthly consumption distributions were plotted according to their cooling category (Fig. 4). Logarithmic scale is used to better observe the distribution difference. On one hand, it can be observed that users who use district cooling their consumption centers around $500 \mathrm{kWh}$ regardless of seasonal changes. This is typically defined as the electricity baseload which refrains from changing throughout the year. On the other hand, users that have cooling as 
part of their electricity bill shift their consumption in accordance with the summer and winter seasons between $3,500 \mathrm{kWh}$ and $1,000 \mathrm{kWh}$ respectively. The modulating effects of cooling show the need of integrating a variable that reflects this relationship appropriately. Therefore, for a monthly analysis, mean outdoor temperature is included as a variable that reflects seasonal weather variations.

Monthly distributions of users with district cooling in 2020 were compared against the monthly distribution of the previous year. Differences between them were assessed using the Mann-Whitney $U$ test, which is a non-parametric test to estimate differences in between distributions (Tables 2 and 3). The alternative hypothesis of the test states that one distribution is stochastically greater than the other, indicating there is a difference between the two distributions. Mann-Whitney $U p$-values in Table 2 show that there is significant evidence to consider the monthly distributions of summer 2020 , which were affected by COVID, different from the consumption distributions of 2019. Given Dubai's government implemented COVID restrictions at the end of March 2020, it is unlikely that the drastic variation in March 2020 is attributed to COVID effects. More information is needed to

Table 2: Monthly distributions mean values and Mann-Whitney $U p$-val for users with externalized cooling in 2020.

\begin{tabular}{|c|cccc|}
\hline Month & Mean 2019 & Mean 2020 & $\begin{array}{c}\text { Mann-Whitney } \\
p \text {-val }\end{array}$ & $\begin{array}{c}\text { Year to year } \\
\text { change }\end{array}$ \\
\hline Jan. (01) & 441 & 504 & 0.1433 & $14 \%$ \\
Feb. (02) & 370 & 409 & 0.1383 & $10 \%$ \\
Mar. (03) & 431 & 317 & $0.0000^{*}$ & $-26 \%$ \\
Apr. (04) & 487 & 562 & $0.0011^{*}$ & $15 \%$ \\
May (05) & 500 & 580 & $0.0009^{*}$ & $16 \%$ \\
Jun. (06) & 423 & 601 & $0.0000^{*}$ & $42 \%$ \\
Jul. (07) & 492 & 610 & $0.0001^{*}$ & $24 \%$ \\
Sep. (09) & 516 & 573 & 0.0509 & $11 \%$ \\
Oct. (10) & 547 & 540 & 0.7915 & $-1 \%$ \\
Nov. (11) & 467 & 544 & $0.0018^{*}$ & $16 \%$ \\
Dec. (12) & 432 & 531 & $0.0002^{*}$ & $23 \%$ \\
\hline
\end{tabular}

Table 3: Monthly distributions mean values and Mann-Whitney $U p$-val for users with cooling included, 2020.

\begin{tabular}{|c|cccc|}
\hline Month & Mean 2019 & Mean 2020 & $\begin{array}{c}\text { Mann-Whitney } \\
p \text {-val }\end{array}$ & $\begin{array}{c}\text { Year to year } \\
\text { change }\end{array}$ \\
\hline Jan. (01) & 1,118 & 1,082 & 0.7853 & $-3 \%$ \\
Feb. (02) & 889 & 921 & $0.0372^{*}$ & $4 \%$ \\
Mar. (03) & 1,155 & 760 & $0.0000^{*}$ & $-34 \%$ \\
Apr. (04) & 1,875 & 1,831 & 0.4213 & $-2 \%$ \\
May (05) & 2,632 & 2,676 & 0.2703 & $2 \%$ \\
Jun. (06) & 3,392 & 3,669 & $0.0004^{*}$ & $8 \%$ \\
Jul. (07) & 3,675 & 4,144 & $0.0000^{*}$ & $13 \%$ \\
Sep. (09) & 3,462 & 3,874 & $0.0002^{*}$ & $12 \%$ \\
Oct. (10) & 2,865 & 2,944 & 0.5268 & $3 \%$ \\
Nov. (11) & 1,586 & 2,013 & $0.0000^{*}$ & $27 \%$ \\
Dec. (12) & 1,105 & 1,465 & $0.0000^{*}$ & $33 \%$ \\
\hline
\end{tabular}


investigate the sudden dip of electricity consumption in March 2020. It is important to mention that the monthly average residential consumption increased by $25 \%$ between April and July 2020 compared to the previous year, which correlates with the lockdown and home curfew policies implemented during the period. This observation is in line with existing literature where residential energy demand increased over the lockdown period. For instance, a 14\% of increase in the residential sector is recorded in Victoria, Australia comparing to prelockdown period [9].

We developed a model with the explanatory variables given in Table 4. To reflect the effects of COVID, we define a dummy variable representing if the current month was affected by a curfew or lockdown order due to the pandemic, i.e. April, May and June of 2020 in Dubai. Two OLS (Ordinary Least Squares) regression models were generated for each cooling category, i.e., cooling included or excluded (district cooling) from the electrical bill. Finally, the predicted variable, electricity consumption, is transformed to the logarithm scale to reduces the skewness of the original distribution. Both models are defined according to eqn (1).

$$
\begin{gathered}
\log (\text { consumption })=B_{o}+B_{\text {occ }} \cdot \text { OCC }+B_{\text {temp }} \cdot T+B_{\text {room }} \cdot B R M \\
+D_{G F A} \cdot S Q M+D_{\text {covid }} \text { COVID }+\varepsilon .
\end{gathered}
$$

Table 4: Model variable definitions.

\begin{tabular}{|lll|}
\hline Variable & Type & Abbreviation \\
\hline Monthly consumption & Float & consumption \\
Number of occupants & Integer & OCC \\
Number of bedrooms & Integer & BRM \\
Gross floor area & Categorical (6) & SQM \\
COVID restrictions were in place & Boolean (2) & COVID \\
Average outdoor temperature & Float & T \\
\hline
\end{tabular}

Linear model results are shown in Table 5. As expected, the model that includes cooling seems to better explain the consumption of the user $\left(\mathrm{R}^{2}=0.648\right)$, while the model that targets for district cooling users performs poorly $\left(\mathrm{R}^{2}=0.357\right)$. Furthermore, the prediction power of the models is presented in Fig. 5, where the $\mathrm{x}$ axis denotes the actual electricity consumption of users, and the $\mathrm{y}$ axis represents the corresponding predicted values. The model that includes cooling have the data along the $45^{\circ}$ line, while the cooling excluded model has a greater spread away from the diagonal line and deviates the most on the high consuming accounts. This result makes sense when comparing the $t$ values of the coefficients with $99.9 \%$ confidence $(t>3.291)$. The most significant variable for cooling included and district cooling model is outdoor temperature and the intercept baseload respectively. While being statistically significant, the temperature coefficient for the district cooling model is minimal (0.01), suggesting the seasonal change has very little influence on the electricity consumption of these accounts. Such results are in line with the facts that the accounts are either a weather driven (cooling included) or baseload driven (district cooling).

When comparing the COVID effects for both models, the covid variable is insignificant for the model that includes cooling while its significant for the district cooling one. On one hand, the lack of significance for the cooling model can be explained through the fact that residents in Dubai tend to leave their HVAC systems on even during unoccupied times especially in summer due to extreme weather conditions. Moreover, cooling takes more than 
Table 5: Linear model parameters.

\begin{tabular}{|c|c|c|c|c|}
\hline & $\begin{array}{l}\text { Cooling } \\
\text { included }\end{array}$ & $\begin{array}{c}\text { Cooling } \\
\text { excluded }\end{array}$ & $\begin{array}{l}\text { Cooling } \\
\text { included }\end{array}$ & $\begin{array}{c}\text { Cooling } \\
\text { excluded }\end{array}$ \\
\hline $\mathrm{R}^{2}$ & 0.648 & 0.357 & & \\
\hline$\sigma-\log (\mathrm{kWh})$ & 0.6314 & 0.6306 & & \\
\hline & \multicolumn{2}{|c|}{ Coeff } & \multicolumn{2}{|c|}{ t-value } \\
\hline Bo & 2.98 & 4.77 & $86.3^{*}$ & $101.9 *$ \\
\hline $\mathrm{D}_{\mathrm{GFA}}(2)$ & -0.07 & 0.00 & -2.3 & 0.0 \\
\hline $\mathrm{D}_{\mathrm{GFA}}(3)$ & 0.08 & 0.11 & 2.6 & 3.0 \\
\hline $\mathrm{D}_{\mathrm{GFA}}(4)$ & 0.25 & 0.22 & $8.3^{*}$ & $5.7 *$ \\
\hline $\mathrm{D}_{\mathrm{GFA}}(5)$ & 0.35 & 0.20 & $11.7^{*}$ & $4.7 *$ \\
\hline $\mathrm{D}_{\mathrm{GFA}}(6)$ & 0.44 & 0.21 & $14.3^{*}$ & $4.8^{*}$ \\
\hline $\mathrm{B}_{\mathrm{occ}}$ & 0.09 & 0.05 & $30.6^{*}$ & $10.1^{*}$ \\
\hline $\mathrm{B}_{\text {temp }}$ & 0.09 & 0.01 & $125.5^{*}$ & $6.2^{*}$ \\
\hline $\mathrm{B}_{\text {room }}$ & 0.30 & 0.30 & $71.8^{*}$ & $36.3 *$ \\
\hline $\mathrm{D}_{\text {covid }}$ & -0.02 & 0.20 & -1.8 & $11.3 *$ \\
\hline
\end{tabular}

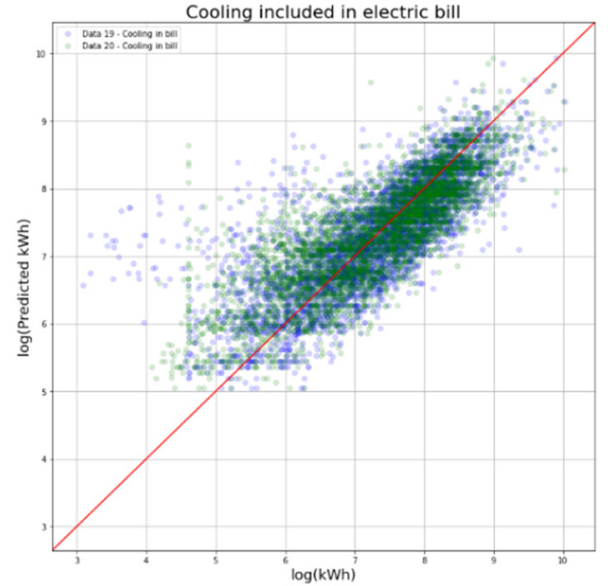

(a)

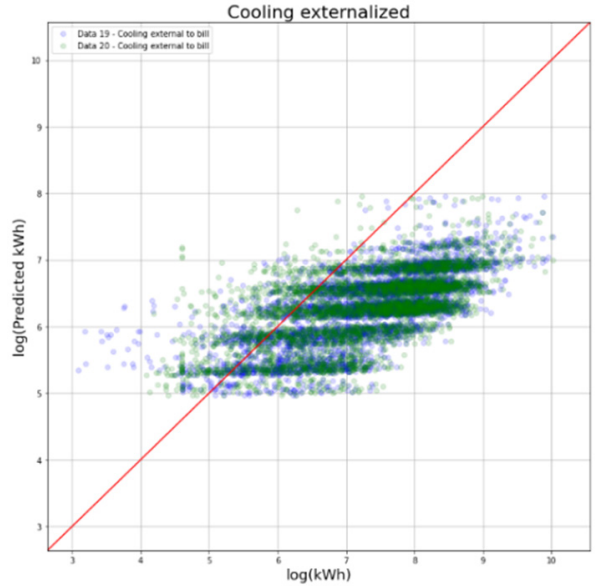

(b)

Figure 5: Actual vs predicted log (consumption) (kWh).

$70 \%$ of the electricity consumption in Dubai, leaving the baseload variation shadowed under the cooling needs. Therefore, most changes can be attributed to cooling related variables such as temperature as cooling plays a more significant role than any other drivers including COVID restrictions. On the other hand, when observing the COVID effects for the users that have district cooling, the influence of COVID becomes significant. This can be explained that measured consumption of the district cooling users represents their baseload consumption. Changes in their dwelling patterns as well as the need of distance learning/working will impact directly on their electrical baseload.

Since the OLS benchmarking model shows limited fit for users with district cooling, and there is no other information available at the current state, multiple distributions were fitted 
to the baseload consumption in hope to define a basic benchmarking model. Fig. 6 shows the top five best fits for the data where the exponentially modified Gaussian distribution (exponnorm) displayed the minimum sum of square errors (Table 6). The probability density function of the exponnorm distribution follows eqns (2) and (3) with fitted parameters to be $K=6.30, \mu=122.56$ and $\sigma=59.16$. This distribution will serve as the preliminary benchmark to rank users that have separate electricity and cooling bills and reflects the distribution of their baseload.

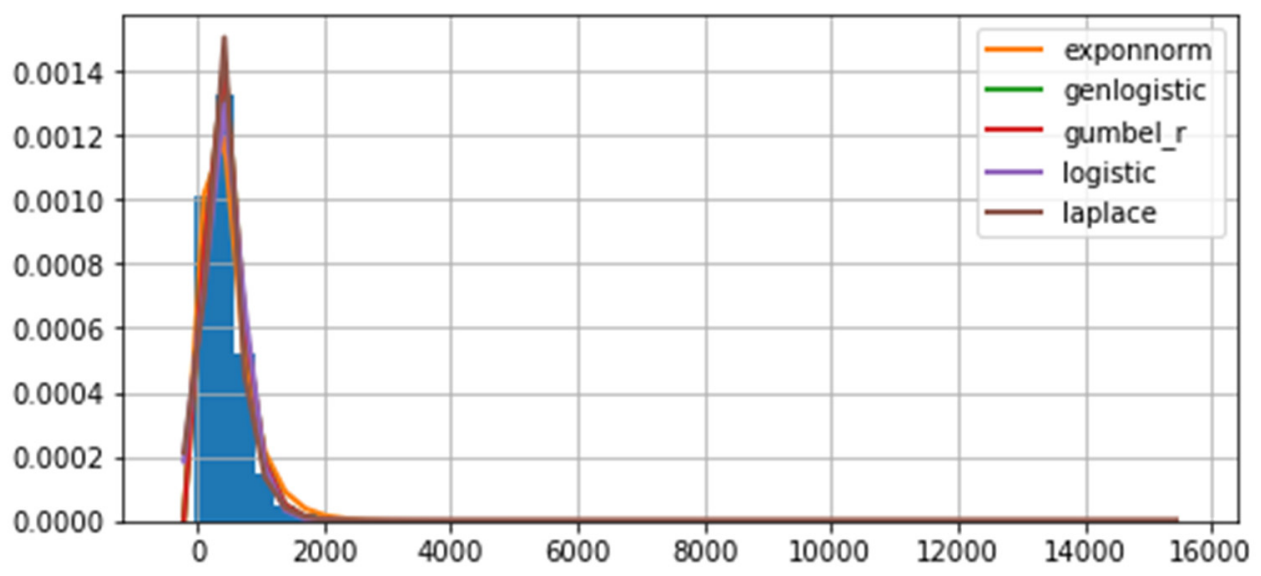

Figure 6: Fitted distributions to consumption with externalized cooling.

Table 6: Distribution fitness for externalized cooling consumption.

\begin{tabular}{|c|c|}
\hline Distribution type & Sum square error \\
\hline exponnorm & $2.55 \mathrm{e}-08$ \\
genlogistic & $4.66 \mathrm{e}-08$ \\
gumbel_r & $4.70 \mathrm{e}-08$ \\
logistic & $1.38 \mathrm{e}-07$ \\
laplace & $1.73 \mathrm{e}-07$ \\
\hline
\end{tabular}

$$
\begin{gathered}
f(x ; \mu, \sigma, \lambda)=\frac{\lambda}{2} e^{\frac{\lambda}{2}\left(2 \mu+\lambda \sigma^{2}-2 x\right)} \operatorname{erfc}\left(\frac{\mu+\lambda \sigma^{2}-x}{\sqrt{2} \sigma}\right), \\
K=\frac{1}{\sigma \lambda} .
\end{gathered}
$$

The above results show that the influence of COVID policies is better highlighted through a baseload analysis which ignores the weather effects on cooling [9]. Similar situation is observed in China, where baseload end uses such as cooking and lighting demand increased over the lockdown period [24]. In Raman and Peng [25] daily new cases of COVID are found to be a dominant driver for Singaporean households energy demand.

When cooling is included in their utility bill, the weather turns to be the biggest energy driver which masks most of the effects of COVID. Furthermore, in this case study, the electrical utility provider operates separately from the district cooling providers. Consequently, it is a complex task to get a holistic understanding of changes both in the 
baseload and in the variable load. Such challenge raises the importance for analyzing users through disaggregated loads and smart meters that will allow to better identify the drivers for users and the changes in their energy patterns.

Finally, it is important to know that even though this study investigates the benchmarking system with consumption records $(\mathrm{kWh})$, a typical benchmarking analysis is usually based on energy use intensities (EUI, $\mathrm{kWh} / \mathrm{m}^{2}$ ). Such limitation is a result of the available survey data which collected gross floor area information under categorical options. Further analysis requires the gross floor area as continuous variable for each user. Such information can be obtained by generating a new survey campaign or integrating user information from other agencies such as the Dubai Land Department.

\section{CONCLUSIONS}

The results show that integrating consumption records with user profiles is valuable to disaggregate consumers. Effects of the main energy drivers will be better observed when grouping the users according to their profiles.

When grouped with cooling sources, Mann-Whitney tests demonstrate there is a significant difference in consumption between 2019 and 2020, particularly for months under movement restrictions. This suggests the need to incorporate the influence of COVID in energy benchmarks to ensure accuracy during affected months. Two OLS models including COVID influence as a dummy variable are made separately according to their cooling category. For district cooling users, the significant coefficient of COVID effect confirms the need of adjusting benchmarks during months that are under the influence of COVID curbing polices.

However, COVID effects are insignificant when analyzed for users who include cooling in their electrical consumption. As $70 \%$ of the electricity consumption of buildings are comprised of cooling in the region [26], its variation outweighs any effects of COVID policies. Consequently, the need of an adjusted benchmark system for users with cooling included in their electricity bills is not as prominent as the one for baseload users in Dubai.

\section{REFERENCES}

[1] Johns Hopkins University, COVID-19 Dashboard, 2021.

[2] Mofijur, M. et al., Impact of COVID-19 on the social, economic, environmental and energy domains: Lessons learnt from a global pandemic. Sustainable Production and Consumption, 26(2020), pp. 343-359, 2021. DOI: 10.1016/j.spc.2020.10.016.

[3] Telecommunications and Digital Government Regulatory Authority, Primary governmental efforts to contain COVID-19, 2021. https://u.ae/en/information-andservices/justice-safety-and-the-law/handling-the-covid-19-outbreak/governmentefforts-to-contain-covid-19.

[4] Garda World, Crisis - News Alerts. https://www.garda.com/crisis24/news-alerts.

[5] The National, Coronavirus in the UAE: All of your questions answered. UAE: The National, 2020.

[6] FCSA, The UAE government's initiatives to combat the COVID-19 crisis, 2020.

[7] COVID-19 Community Mobility Report: United Arab Emirates - Apr. 2020, 2020. google.com/covid19/mobility.

[8] Bielecki, S., Dukat, P., Skoczkowski, T., Sobczak, L., Buchoski, J. \& Maciag, Ł., Impact of the lockdown during the COVID-19 pandemic on electricity use by residential users. Energies, 14(4), pp. 1-32, 2021. DOI: 10.3390/en14040980. 
[9] Snow, S., Bean, R., Glencross, M. \& Horrocks, N., Drivers behind residential electricity demand fluctuations due to COVID-19 restrictions. Energies, 13(21), 2020. DOI: 10.3390/en13215738.

[10] Aaron, K. \& Ember, S., Explaining the economic impact of COVID-19: Core industries and the Hispanic workforce, 2021. https://digitalscholarship.unlv.edu/cgi/ viewcontent.cgi?article $=1001 \&$ context $=$ brookings_policybriefs_reports.

[11] Evans, C., The coronavirus crisis and the technology sector. Business Economics, 55(4), pp. 253-266, 2020. DOI: 10.1057/s11369-020-00191-3.

[12] Edomah, N. \& Ndulue, G., Energy transition in a lockdown: An analysis of the impact of COVID-19 on changes in electricity demand in Lagos Nigeria. Global Transitions, 2, pp. 127-137, 2020. DOI: 10.1016/j.glt.2020.07.002.

[13] Vogt, Y., Top-down energy modeling. Strategic Planning for Energy and the Environment, 22(4), pp. 64-79, 2003. DOI: 10.1080/10485230309509626.

[14] Tereci, A., Ozkan, S.T.E. \& Eicker, U., Energy benchmarking for residential buildings. Energy and Buildings, 60, pp. 92-99, 2013. DOI: 10.1016/j.enbuild.2012.12.004.

[15] Shabunko, V., Lim, C.M. \& Mathew, S., EnergyPlus models for the benchmarking of residential buildings in Brunei Darussalam. Energy and Buildings, 169, pp. 507-516, 2018. DOI: 10.1016/j.enbuild.2016.03.039.

[16] Ding, Y. \& Liu, X., A comparative analysis of data-driven methods in building energy benchmarking. Energy and Buildings, 209, 109711, 2020.

DOI: $10.1016 /$ j.enbuild.2019.109711.

[17] Arjunan, P., Poolla, K. \& Miller, C., EnergyStar++: Towards more accurate and explanatory building energy benchmarking. Applied Energy, 276, 115413, 2020.

DOI: 10.1016/j.apenergy.2020.115413.

[18] DEWA, My sustainable living programme. https://www.dewa.gov.ae/en/consumer/ consumption-management/my-sustainable-living-programme.

[19] DEWA, Utilities and bills. https://www.dubaipulse.gov.ae/category/utilities-bills.

[20] Deng, H., Fannon, D. \& Eckelman, M.J., Predictive modeling for US commercial building energy use: A comparison of existing statistical and machine learning algorithms using CBECS microdata. Energy and Buildings, 163, pp. 34-43, 2018. DOI: 10.1016/j.enbuild.2017.12.031.

[21] Attia, S., Mustafa, A., Giry, N., Popineau, M., Cuchet, M. \& Gulirmak, N., Developing two benchmark models for post-World War II residential buildings. Energy and Buildings, 244, 111052, 2021. DOI: 10.1016/j.enbuild.2021.111052.

[22] Chung, W., Review of building energy-use performance benchmarking methodologies. Applied Energy, 88(5), pp. 1470-1479, 2011.

DOI: 10.1016/j.apenergy.2010.11.022.

[23] Khoshbakht, M., Gou, Z. \& Dupre, K., Energy use characteristics and benchmarking for higher education buildings. Energy and Buildings, 164, pp. 61-76, 2018.

DOI: 10.1016/j.enbuild.2018.01.001.

[24] Jiang, P., Van Fan, Y. \& Klemeš, J.J., Impacts of COVID-19 on energy demand and consumption: Challenges, lessons and emerging opportunities. Applied Energy, 285, 2021. DOI: 10.1016/j.apenergy.2021.116441.

[25] Raman, G. \& Peng, J.C.-H., Electricity consumption of Singaporean households reveals proactive citizen response to COVID-19 progression, 2020. https://europepmc.org/article/PPR/PPR255519.

[26] Afshari, A., Nikolopoulou, C. \& Martin, M., Life-cycle analysis of building retrofits at the urban scale-a case study in United Arab Emirates. Sustain., 6(1), pp. 453-473, 2014. DOI: $10.3390 / \mathrm{su} 6010453$. 